\title{
Manageable risk factors associated with the lactational incidence, elimination, and prevalence of Staphylococcus aureus intramammary infections in dairy cows
}

\author{
S. Dufour, ${ }^{*} \dagger^{1}$ I. R. Dohoo, ${ }^{\star} \ddagger$ H. W. Barkema, ${ }^{\star} \S$ L. DesCôteaux, ${ }^{*}$ T. J. DeVries, ${ }^{*}$ II K. K. Reyher, ${ }^{*} \ddagger$ J.-P. Roy, ${ }^{*}$ \\ and D. T. Scholl* ${ }^{2}$ \\ ${ }^{*}$ Canadian Bovine Mastitis Research Network, C.P. 5000, St-Hyacinthe, Quebec, J2S 7C6, Canada \\ †Department of Pathology and Microbiology, Faculty of Veterinary Medicine, University of Montreal, C.P. 5000, St-Hyacinthe, Quebec, \\ J2S 7C6, Canada \\ $\ddagger$ Atlantic Veterinary College, University of Prince Edward Island, 550 University Ave, Charlottetown, PEI, C1A 4P3, Canada \\ §Department of Production Animal Health, Faculty of Veterinary Medicine, University of Calgary, 3300 Hospital Drive NW, Calgary, \\ Alberta, T2N 4N1, Canada \\ \#Department of Clinical Sciences, Faculty of Veterinary Medicine, University of Montreal, C.P. 5000, St-Hyacinthe, Quebec, J2S 7C6, Canada \\ IIDepartment of Animal and Poultry Science, University of Guelph, Kemptville Campus, 830 Prescott St., Kemptville, Ontario, K0G 1J0, Canada
}

\begin{abstract}
Staphylococcus aureus intramammary infections (IMI) are a major cause of mastitis on farms worldwide. Incidence and elimination rates are the key determinants of prevalence of Staph. aureus, and risk factors associated with these rates must be identified, prioritized, and controlled to obtain long-term reduction in prevalence. The objectives of this study were to identify manageable risk factors associated with the lactational incidence, elimination, and prevalence of Staph. aureus IMI. A cohort of 90 Canadian dairy farms was recruited and followed in 2007 and 2008. Quarter milk samples were collected repeatedly from a selection of cows, and bacteriological culture was realized to assess incidence, elimination, and prevalence of Staph. aureus IMI. Practices used on farms were measured using direct observations and a validated questionnaire. A linear regression model was used to explore the relationship between herd IMI prevalence and incidence and elimination rates. Multilevel logistic regression models were used to compute measures of associations between practices used on farms and IMI incidence, elimination, and prevalence. The herd incidence rate was the most important predictor of herd IMI prevalence: a reduction of the incidence rate equivalent to its interquartile range (0.011 new IMI/quarter-month) was associated with a prevalence reduction of 2.2 percentage points; in comparison, an equivalent increase of the elimination rate by its interquartile range ( 0.36 eliminated IMI/ quarter-month) resulted in a prevalence reduction of
\end{abstract}

Received July 8, 2011.

Accepted November 14, 2011.

${ }^{1}$ Corresponding author: simon.dufour@umontreal.ca

${ }^{2}$ Current address: College of Agriculture and Biological Sciences, South Dakota State University, Brookings, SD 57007.
0.4 percentage points. Postmilking teat disinfection and blanket dry-cow therapy were already implemented by most herds. Most of the practices associated with Staph. aureus IMI incidence were related to milking procedures. Among these, wearing gloves during milking showed desirable associations with IMI incidence, elimination, and prevalence. Similarly, adequate teat-end condition and use of premilking teat disinfection were associated with lower IMI incidence and prevalence. The initial herd prevalence of Staph. aureus IMI was positively associated with subsequent IMI incidence. This indicates that, in some situations, an initial reduction of the pool of infected quarters could be justified. Some housing practices were associated with IMI incidence, elimination, or prevalence. The effects of these latter practices, however, were often influenced by specific cow characteristics such as parity or days in milk. These results highlight the importance of good milking practices to prevent Staph. aureus IMI acquisition and, therefore, reduce their prevalence.

Key words: dairy cow, mastitis, Staphylococcus aureus, incidence

\section{INTRODUCTION}

Mastitis is one of the most costly diseases for the dairy industry worldwide. The term mastitis encompasses 2 relatively independent health problems: clinical and subclinical mastitis (Barkema et al., 1998; Olde Riekerink et al., 2008a). Clinical mastitis is an easily observable disease and, for this reason, risk factors associated with prevalence or incidence of clinical mastitis have been the primary focus of much research in the last few decades. Conversely, although SCC can be used to identify potentially infected quarters, accurate identification of subclinical mastitis requires collection 
and bacteriological culture of milk samples and is, therefore, more complex and expensive to achieve. In addition, detection of new IMI requires repeated milk collection and culture. Because of this latter difficulty, almost all risk factor studies for pathogen-specific subclinical mastitis have focused on association with IMI prevalence (the proportion of quarters infected at a given point in time) rather than IMI incidence (the number of newly arising IMI per quarter per period of time). Interpretation of associations reported in cross-sectional prevalence studies, however, is complex because the time order of occurrence between the potential exposure and the disease is not known; it is, therefore, difficult to differentiate the cause from the consequence (Rothman et al., 2008).

Despite a decrease in bulk milk SCC in many countries, Staphylococcus aureus remains a major cause of subclinical mastitis. The herd prevalence of Staph. aureus as determined by bulk tank culture is still high: 2 recent North American surveys suggest that 50 to $75 \%$ of herds have at least one cow with IMI by this contagious pathogen (USDA-APHIS, 2008; Olde Riekerink et al., 2010). Other recent studies have reported cow prevalence of Staph. aureus of $6.4 \%$ in a random sample of cows in Switzerland (Moret-Stalder et al., 2009), 3.7 and $15.0 \%$ in low and high SCC cows, respectively, in the Netherlands (Sampimon et al., 2009), and 22.2\% in a random sample of cows in Norway (Østerås et al., 2006). The effect of these IMI is considerable; quarters infected with Staph. aureus had a mean geometric SCC of 333,000 cells/mL of milk (95\% CI: $320,000-348,000$ cells/mL) compared with 68,000 cells/mL for uninfected quarters (Djabri et al., 2002). In the latter study, the effect of a Staph. aureus IMI was estimated to be a 5-fold increase in SCC. The economic loss associated with subclinical mastitis caused by a Staph. aureus IMI was estimated by Wilson et al. (1997) at US $\$ 170$ per lactation.

Some important characteristics of Staph. aureus organisms are their ability to cause persistent IMI and their relatively important resistance to conventional treatments (Barkema et al., 2006). In addition, quarters recovering from Staph. aureus IMI have been shown to have increased susceptibility to reinfection (Zadoks et al., 2002). These characteristics imply that control of Staph. aureus will rarely be achieved by treatment of existing IMI. To lower the prevalence of Staph. aureus IMI, manageable risk factors associated with acquisition of these IMI (IMI incidence) have to be identified. Alternatively, an understanding of manageable risk factors associated with duration or elimination of existing IMI would also be valuable. These latter risk factors could be related, among other things, to improved host resistance to IMI or differential selection of less persistent strains of Staph. aureus.

The study presented is a longitudinal cohort study on naturally acquired Staph. aureus IMI during lactation on 90 Canadian dairy herds. The objectives were to estimate the effect of manageable risk factors on incidence, elimination, and prevalence of Staph. aureus IMI, taking into consideration the effects of other farm conditions and practices.

\section{MATERIALS AND METHODS}

The herds selected were participants in the National Cohort of Dairy Farms (NCDF) of the Canadian Bovine Mastitis Research Network (CBMRN). A thorough description of the herd selection process and general characteristics of the NCDF herds can be found in Reyher et al. (2011). Briefly, 91 dairy herds were recruited in 2006 in 4 regions of Canada based on the willingness of dairy producers to participate in the 2-yr data collection (2007 and 2008). One herd refused to continue participation in the NCDF after the beginning of the study in 2007 because of the amount of work involved. The present study is limited to the 90 herds that contributed to the cohort for at least $1 \mathrm{yr}$.

\section{Milk Sampling}

Series of milk samples were collected on 4 different occasions (referred to as "sampling periods" in the remainder of the article) in 2007 and 2008 (March-May 2007, June-August 2007, January-March 2008, and June-August 2008). At the beginning of each sampling period, a new sample of apparently normal milking cows was selected in each herd (Reyher et al., 2011). This sample consisted of 15 lactating cows: 10 randomly chosen cows and the 5 most recently freshened cows. Cows selected in a previous sampling period were not excluded from the selection process in subsequent sampling periods. During each sampling period, milk from each quarter of the selected cows was collected by a team of trained technicians on 3 occasions at intervals of 3 wk to constitute series of 3 milk samples per quarter. Signs of inflammation of the quarters were noted if present. As part of the CBMRN cohort-sampling scheme, NCDF producers were also asked to record clinical mastitis events and submit milk samples for these cows. During the 2-yr course of the cohort study, none of the apparently normal lactating cows selected for the present study suffered from clinical mastitis during the sampling periods. Technicians, however, recorded flakes in the milk without additional signs of inflammation when collecting milk of $72(0.12 \%)$ 
quarters. These samples were not excluded from the analyses. Teat-end condition scores (Neijenhuis et al., 2000) were recorded at the first and last samplings of each series. Bacteriological culture of the milk samples was accomplished by a uniform protocol that was based on National Mastitis Council guidelines (Reyher et al., 2011). Briefly, $10 \mu \mathrm{L}$ of milk was streaked on a Columbia agar $+5 \%$ sheep blood plate and incubated aerobically at $35^{\circ} \mathrm{C}$ for $24 \mathrm{~h}$. The different types of colonies were then enumerated (up to 10 colonies) and speciated after $24 \mathrm{~h}$ using recommended bacteriologic procedures (Hogan et al., 1999) and reincubated for another $24 \mathrm{~h}$. Somatic cell count analysis was performed using the Fossomatic milk cell counter (4000 series, Foss Electric, Hillerød, Denmark).

For the organism of interest (Staph. aureus) and for CNS, Corynebacterium spp., Streptococcus uberis, Streptococcus dysgalactiae, and streptococci other than Strep. uberis, Strep. dysgalactiae, and Strep. agalactiae (referred to as "other streptococci" in the remainder of the article), presence of an IMI on the day that an individual milk sample was collected was defined as recovery of the organism in concentration of $\geq 100 \mathrm{cfu} /$ $\mathrm{mL}$ of milk in the associated sample. These definitions were chosen based on the recently reported sensitivities and specificities of various IMI definitions for single milk samples (Dohoo et al., 2011). Based on results from Höfler (2005), the definitions of IMI based on recovery of $\geq 100 \mathrm{cfu}$ of a pathogen $/ \mathrm{mL}$ of milk yielded sensitivity and specificity combinations that would best control the misclassification bias for the different pathogens recovered.

\section{Data Sets}

Separate data sets for each of the 3 outcomes of interest (incidence, elimination, and prevalence of Staph. aureus IMI) were created. For the incidence and elimination data sets, the series of 3 milk samples collected from a specific quarter during a sampling period was organized in pairs (samples 1 and 2, samples 2 and 3 ), and only pairs with complete results were retained. Pairs negative for Staph. aureus on the first sample of the pair were considered at risk and determined to have an incident infection if they were positive on the following sample. Pairs that were positive on the first sample of the pair were at risk of an elimination, which was deemed to have occurred if the subsequent sample was negative.

For the prevalence data set, the series of 3 milk samples collected on a specific quarter during a sampling period was considered as one observation. A prevalent Staph. aureus IMI was defined as a series in which $\geq 1$ of the 3 samples collected was found to be positive for Staph. aureus. Series in which no samples tested positive for Staph. aureus were defined as free of Staph. aureus IMI.

\section{Explanatory Variables}

This study was designed to identify risk factors at the herd, cow, and quarter levels. A thorough selection of potential risk factors, confounders, and measure-of-effect modifiers was first performed and is fully described in Dufour et al. (2010). Variables selected were then measured using direct observations and a validated bilingual questionnaire with known sensitivity and specificity (Dufour et al., 2010). The questionnaire was administered on multiple occasions, which allowed the identification of any changes in the practices used during the 2-yr study, and the date at which that change had occurred was recorded. Because of the high proportion of dairy producers reporting at least one modification to their milking procedures $(27 \%)$ or to their housing management (33\%) over a period of 6 mo (Dufour et al., 2010), the management practices employed just before and during a specific sampling period were analyzed rather than merely those in use at the beginning of the study. At all times during the analysis, time order of occurrence between exposure and disease was taken into consideration. Pathogen-specific quarter, cow, and herd prevalences of IMI at the first sampling were used as explanatory variables. Dairy Herd Improvement data from 2005 to 2009 were obtained for each participating herd to capture data on individual milk production, cow and herd level SCC, and herd demographics. As for questionnaire data, attention was given to DHI data related to the period immediately preceding a sampling period. Contextual effects were taken into consideration during variable selection and construction. Contextual effects can be defined as the effect of a group-level characteristic on an individual outcome and should specifically be investigated whenever a group-level variable provides information that is not captured by the individual-level variable (Diez-Roux, 1998). For instance, the risk of becoming infected with Staph. aureus for a negative quarter belonging to a cow with a high proportion of already infected quarters might differ from that of a quarter belonging to a herd with a high prevalence of infection. In one case (cow prevalence), the effect is theoretically linked to within cow transmission of IMI, whereas in the other (herd prevalence, the contextual effect) between cow transmission is involved. The prevalence of Staph. aureus in both the cow and herd are, therefore, of interest because they represent different concepts.

The focus of the study was on risk factors that could be manipulated to modulate Staph. aureus IMI incidence, elimination, or prevalence. Consequently, only 
variables that could be modified relatively easily were considered as manageable risk factors. For this reason, type of housing system was not considered a manageable risk factor; this variable and other nonmanageable variables were included solely as confounders or effect modifiers of the association between manageable risk factors and disease and are referred to as "covariates" in the remainder of the article. Special attention was given to attitudes, motivations, knowledge, and beliefs of dairy producers as potential confounders or effect modifiers of the associations under study. A list of the explanatory variables tested is presented in Table 1. A full description of the data collection process as well as distributions of the manageable risk factors and covariates in the population under study can be found in Dufour et al. (2010).

\section{Analyses}

Data Structure. In all 3 data sets, because cows could be selected in multiple sampling periods, observations from a cow during a specific sampling period could be cross-classified by herd and by period. In the incidence and elimination data sets, although 2 pairs of samples per quarter per sampling period were available, the definitions used for quarter at risk of acquiring or eliminating a Staph. aureus IMI precluded any type of correlation between observations collected on a quarter during a sampling period. For instance, a quarter acquiring a Staph. aureus IMI on the first pair would not be considered at risk of acquiring a new IMI for the second pair; thus, pairs of samples collected on a quarter during a sampling period were truly independent observations. In the prevalence data set, only one observation was available per quarter per sampling period, and clustering of observation per quarter was, therefore, nonexistent. In all 3 data sets, however, observations collected on a specific cow or on a specific herd during a sampling period were correlated. Structure of the data was, therefore, a hierarchical cross-classified structure with observations clustered by cow and cows clustered both by herd and by sampling period. A proportion of $78,19,3$, and $<1 \%$ of the cows in the incidence and prevalence data sets were selected, respectively, for 1 , 2,3 , and all 4 sampling periods, reflecting in part the lower odds of being randomly selected multiple times. In the elimination data set, 89 and $11 \%$ of the cows were selected for 1 and 2 sampling periods respectively. The essential part of the correlation structure was, therefore, clustering of observations by cow and herd.

Statistical Analyses. First, the relative effect of herd incidence and elimination rates on the herd prevalence of IMI was assessed. For this purpose, a linear regression model was used. The dependent variable was the quarter prevalence of Staph. aureus IMI in the herd over the $2 \mathrm{yr}$ of the study, and explanatory variables were the herd incidence and elimination rates during that same period.

Then, for each previously described data set, descriptive analyses of all variables were conducted to identify distributions and detect unlikely values. In one herd, premilking teat disinfection and gloves were used by half of the milkers. Because of the impossibility of correctly classifying this herd for these specific characteristics, observations from this herd were excluded from analyses on premilking teat disinfection and use of gloves. Next, in each data set and for each outcome, unconditional associations were estimated to screen the explanatory variables described in Table 1. To simplify the model building, cross-classification was ignored at this stage of the analyses, and a hierarchical logistic regression model, which accounted for clustering of observations by cow and herd, was used. Hierarchical analyses were performed using the GLIMMIX procedure of SAS 9.2 (SAS Institute Inc., Cary, NC). Parameter estimation was conducted using maximum likelihood (Laplace approximation) whenever possible. Pseudo-likelihood estimation (default estimation method in GLIMMIX) was used whenever maximum likelihood estimation methods could not yield valid estimates. The general model was as follows:

$$
\begin{aligned}
& Y_{\mathrm{ijk}}=\beta_{0 \mathrm{ijk}}+\beta_{1} \mathrm{X}_{\mathrm{ijk}}+\mathrm{v}_{0 \mathrm{k}}+\mathrm{u}_{0 \mathrm{jk}}, \\
& \operatorname{Var}\left(\mathrm{Y}_{\mathrm{ijk}} \mid \pi_{\mathrm{ijk}}\right)=\pi_{\mathrm{ijk}}\left(1-\pi_{\mathrm{ijk}}\right),
\end{aligned}
$$

where $Y_{\mathrm{ijk}}$ is the odds of acquiring a new Staph. aureus IMI, the odds of eliminating an existing Staph. aureus IMI, or the odds of having a prevalent Staph. aureus IMI, for the incidence, elimination, and prevalence analyses, respectively $\left(\mathrm{Y}_{\mathrm{ijk}}\right.$ is a function of explanatory variable $\mathrm{X}$ through the logit function, and approximately follows a binomial distribution); $\beta_{0 \mathrm{ijk}}$ is the intercept; $\beta_{1}$ is the regression coefficient for explanatory variable $\mathrm{X} ; \mathrm{v}_{0 \mathrm{k}}$ and $\mathrm{u}_{0 \mathrm{jk}}$ are the herd and cow random effect, respectively, and approximately follow normal distributions; and $\pi_{\mathrm{ijk}}$ is the probability that $\mathrm{Y}_{\mathrm{ijk}}=1$.

For all continuous variables, the linearity assumption was assessed using plots of the log odds of the variable after categorization into quartiles against the mid-value of each category (Dohoo et al., 2003). Continuous variables were categorized in a biologically meaningful way whenever the linearity assumption could not be met. Variables with $P \leq 0.20$ (Wald test) were retained as potentially important manageable risk factors or covariates. 
Table 1. Summary of explanatory variables analyzed for association with Staph. aureus IMI on 90 Canadian dairy herds, 2007-2008

\begin{tabular}{|c|c|}
\hline Item & Description \\
\hline \multicolumn{2}{|l|}{ Manageable risk factor } \\
\hline 1. Milking procedures & $\begin{array}{l}\text { Uses uniform milking routine; has written milking procedures; milkers receive bonus for milk quality; milker training } \\
\text { frequency; milkers wear gloves; gloves are cleaned during milking; cows are fore-stripped before milking; emplacement } \\
\text { where foremilk is discarded; teat cleaning and drying methods; number of cows per cloth; uses pre- and postmilking teat } \\
\text { disinfection and type of application and frequency of cleaning of applicators; milks cows with high SCC, Staphylococcus } \\
\text { aureus IMI, or clinical mastitis last or with a specific milking unit; milker:cow ratio; milker:milking unit ratio; } \\
\text { cow:milking unit ratio; owner milks cows; uses a technique to keep cows standing after milking; teat end condition }\end{array}$ \\
\hline 2. Milking equipment & $\begin{array}{l}\text { Type of milking system; use of automatic take-off; milking system inspection frequency; vacuum check } \\
\text { frequency; teat-cup replacement frequency; measure milk conductivity during milking }\end{array}$ \\
\hline 3. Stalls and housing management & $\begin{array}{l}\text { Outside access; type and frequency of alley cleaning; stall base; type, amount, and frequency of replacement of bedding in stalls; } \\
\text { frequency of removing manure from stalls; part of the stall that is cleaned; use of a bacteriostatic product in stalls; technique } \\
\text { used to disinfect stalls; cleanliness of cows' flanks, legs, and udder; stall dimensions; uses electric trainers; stocking density }\end{array}$ \\
\hline 4. Maternity pens & $\begin{array}{l}\text { Proportion of calving occurring in a maternity pen (MP); number of MP; ratio MP per cow; use of individual vs. } \\
\text { group MP; days spent in MP before and after calving; MP use for sick cows; MP base; type, amount, and frequency } \\
\text { of replacement of bedding in MP; frequency of removing manure from MP; technique used to disinfect MP }\end{array}$ \\
\hline 5. General management and biosecurity & $\begin{array}{l}\text { Fly control; udder hair management; tail management; vaccinates against coliform mastitis; general vaccination; records } \\
\text { diseases; cow bought:milking cow ratio; tests udder health of purchased cows; routinely uses bacteriological analysis; } \\
\text { routinely uses California Mastitis Test; monitors individual production; reviews individual SCC frequently; has culling } \\
\text { protocols for high SCC, Staph. aureus, and clinical mastitis cows; proportion of cows treated with antibiotics at dry-off }\end{array}$ \\
\hline 6. Nutrition & $\begin{array}{l}\text { Manages calcium in diet around calving; feeding system; milking cows' diet balanced } \\
\text { based on forage analysis; cow and herd milk protein:fat ratio }\end{array}$ \\
\hline 7. Management of clinical cases & $\begin{array}{l}\text { Proportion of clinical mastitis treated; treatment duration; uses teat disinfection before intramammary (IMM) treatment; } \\
\text { uses complete vs. partial insertion for IMM treatment; applies postmilking teat disinfection after IMM treatment }\end{array}$ \\
\hline 8. Demographics and infection prevalence & $\begin{array}{l}\text { Herd and cow milk yield; herd quarter prevalence of Staph. aureus, CNS, Corynebacterium } \\
\text { spp., Streptococcus uberis, Streptococcus dysgalactiae, and other streptococci }\end{array}$ \\
\hline \multicolumn{2}{|l|}{ Covariates $^{1}$} \\
\hline $\begin{array}{l}\text { 9. Housing type, demographics, } \\
\text { and infection prevalence }\end{array}$ & $\begin{array}{l}\text { Type of housing system; season; mean number of milking cows; herd mean DIM; cow parity and DIM; herd } \\
\text { previous mean linear cell score (LCS); herd mean LCS for the preceding } 24 \text { mo; cow previous LCS from DHI; cow } \\
\text { number of DHI test with LCS > } 4.0 \text { in the last } 3 \text { tests; quarter LCS on first sample; cow and quarter prevalence } \\
\text { of Staph. aureus, CNS, Corynebacterium spp., Strep. uberis, Strep. dysgalactiae, and other streptococci }\end{array}$ \\
\hline 10. Motivations and attitudes & $\begin{array}{l}\text { Herd manager (HM) self-reported meticulousness; HM meticulousness (external evaluation); farm management level (external } \\
\text { evaluation); HM enjoys milking (self-reported); record-keeping completeness (external evaluation); HM wish to reduce bulk } \\
\text { tank SCC (BTSCC); goal for BTSCC; importance of high SCC or Staph. aureus in culling decision; HM worries about } \\
\text { cost of mastitis; udder health is important criteria for bull selection; HM thinks he/she should do more about mastitis } \\
\text { prevention; resource persons used to prevent or solve mastitis problems; rationale for treatment decision of clinical cases }\end{array}$ \\
\hline 11. Knowledge and beliefs & $\begin{array}{l}\text { Cow SCC and BTSCC threshold considered problematic; perceived ease of detecting high SCC } \\
\text { cows; Staph. aureus perceived as an environmental problem; individual SCC measurements are } \\
\text { important; perceived control over mastitis problems; self-evaluated knowledge on mastitis }\end{array}$ \\
\hline
\end{tabular}

cows; Staph aureus perceived as an environmental problem; individual SCC measurements are

${ }^{1}$ Variables listed as covariates were used only as potential confounders or effect modifiers of association between manageable risk factors and Staphylococcus aureus IMI. 
Then, for each manageable risk factor retained, a list of variables that could act as potential confounders of the association between this manageable risk factor and the outcome studied was constituted, using other variables also retained. To be eligible as a confounder of a given association, a variable had to meet 3 criteria: (1) variable is theoretically associated with the manageable risk factor; (2) variable theoretically affects the outcome under study; and (3) variable is not affected by the manageable risk factor nor the outcome (Rothman et al., 2008). Assessment of the criteria for confounding was realized using principles such as time sequence between variables' occurrence and theoretical biological and sociological relationships between variables. The importance of these selected confounders was then assessed by adding them one at the time to the model containing the manageable risk factor and by comparing the proportion of change between the adjusted and crude odds ratio (OR) as described by Mickey and Greenland (1989). Based on their recommendations, potential confounders associated with a change of $\geq 10 \%$ were retained as confounders. Whenever possible, variables used as confounders were left on a continuous scale if continuous, even though the assumption of linearity might have deviated from the model assumptions; categories of categorical variables were not collapsed (Brenner and Blettner, 1997). All retained confounders were then added to the model containing the manageable risk factor to provide a confounding adjusted model. Logically plausible effect modifiers were then identified in the list of variables retained by the unconditional analyses. The importance of these potential effect modifiers was tested as follows: the variable and its cross-product with the manageable risk factor were added to the confounding adjusted hierarchical model, a Wald test was realized on the crossproduct terms, and variables yielding $P \leq 0.05$ were retained as significant measure of effect modifiers.

To adjust estimates of association for the crossclassified structure of the data, revised estimates were obtained for each model in MlWin 2.20 (Rasbash, London, UK) using a Bayesian estimation method and taking into consideration the complete hierarchical cross-classified structure. Bayesian hierarchical crossclassified models were run with a burn-in period of 500; starting values for each parameter were generated using iterative generalized least square estimation; default MlWin Markov chain Monte Carlo sampling methods were used (Metropolis-Hasting sampling with scale factor of 5.8, acceptance rate of $50 \%$, and tolerance rate of $10 \%$ ); they were run for a minimum of 50,000 iterations without thinning. A larger number of iterations was realized when needed to satisfy the Raftery-Lewis diagnostic for the fixed parameters associated with the manageable risk factor and any cross-product terms (Raftery and Lewis, 1992). Visual inspection of the trajectories and posterior distributions of these fixed parameters was realized to ensure properly behaving Markov chain Monte Carlo chains. Assumption of normality of the residuals was checked by visual inspection of plots of standardized residuals against their normal score.

\section{Power of the Study}

Approximate power calculations were realized using MLPowSim 1.0 (Browne, Bristol, UK). The sample size for this specific study was bounded by the prearranged CBMRN sampling methodology. Consequently, retrospective power calculations were realized and power of the study is therefore presented in terms of strength of association detectable with $90 \%$ power between outcome and a binary explanatory variable located at lowest level of a simplified 3-level hierarchy (observation, cow, herd), for a range of exposure prevalences, a significance level of $5 \%$, and given the available sample size and observed outcome distribution. For IMI incidence, our study had at least $90 \%$ power to detect strength of association greater than OR of 1.6, 1.7, and 2.5 (or, alternatively, $<0.63,0.59,0.40)$ for exposure distribution of 50:50, 70:30, and 90:10 respectively. For IMI elimination, our study had at least $90 \%$ power to detect strength of association greater than OR of 2.0,2.2, and 3.2 (or, alternatively, $<0.50,0.45,0.31$ ) for exposure distribution of 50:50, 70:30, and 90:10 respectively. Finally, for IMI prevalence, our study had at least $90 \%$ power to detect strength of association greater than OR of 1.6, 1.7, and 2.2 (or, alternatively, $<0.63,0.59$, 0.45 ) for exposure distribution of 50:50, 70:30, and 90:10 respectively. These power calculations were made with the assumption that exposures and diseases were perfectly measured. In general, more extreme strength of association would be detectable with $90 \%$ power for variables defined at a higher level of the hierarchy (cow or herd variables).

\section{RESULTS}

Herds selected had a mean of 85 milking cows (range 32 to 326 ) and mean 305-d milk production of $9,781 \mathrm{~kg}$ of milk (range 7,734 to 12,377 ). Over the 2-yr study, 59,167 quarter milk samples were collected in the selected sampling intervals. Sixty-seven samples were lost or damaged before bacteriological culture could be conducted. Staphylococcus aureus was cultured from $1,504(2.5 \%)$ of the 59,100 quarter milk samples for which culture results were available. Distributions of herd Staph. aureus IMI incidence rate, elimination 
a) Herd IMI incidence rate

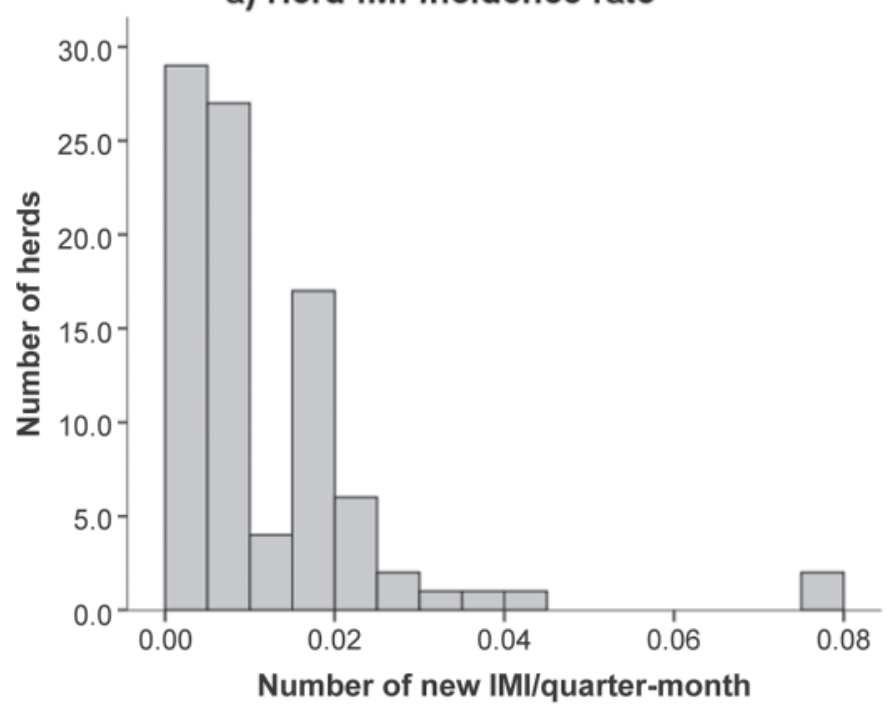

c) Herd IMI prevalence

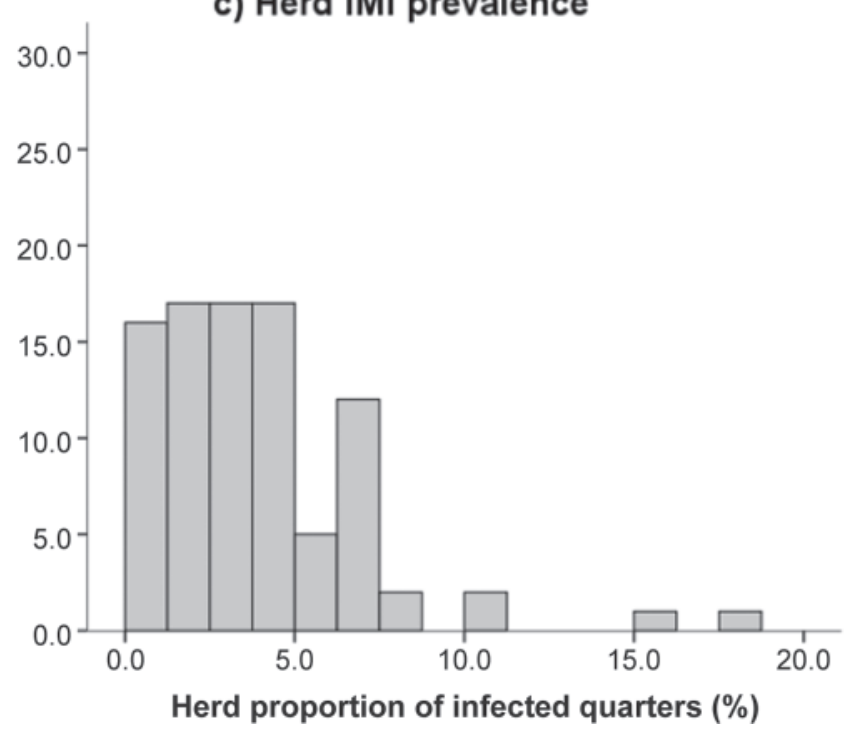

b) Herd IMI elimination rate

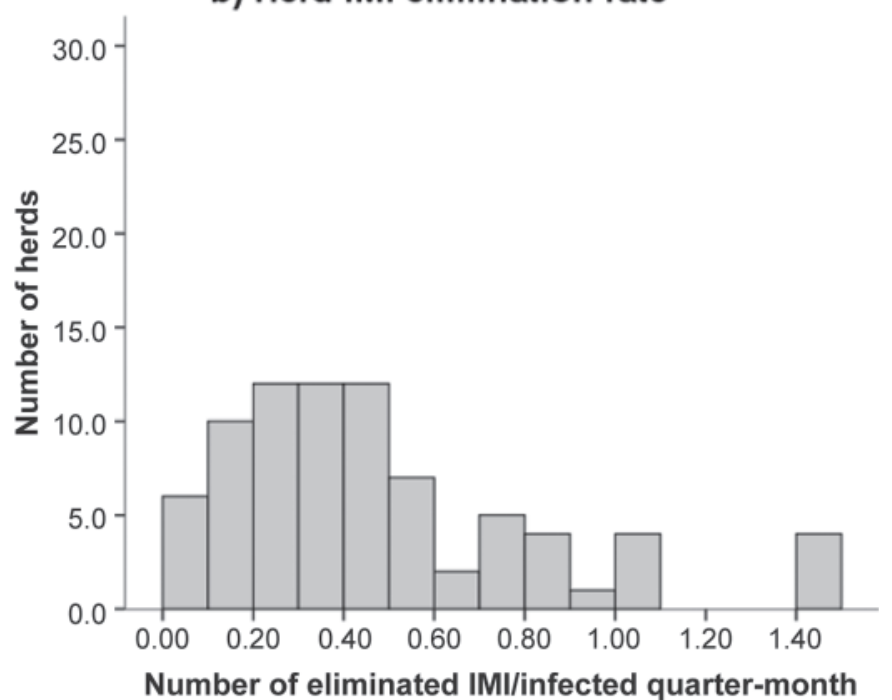

Figure 1. Herd Staphylococcus aureus IMI incidence rate, elimination rate, and prevalence distributions.

rate, and prevalence are presented in Figure 1. One striking feature was the skewness of the incidence rate distribution, with $92.2 \%$ of the NCDF herds having an incidence rate of $\leq 0.02$ new Staph. aureus IMI/quartermonth and only a few herds having an incidence rate $>0.02$, but up to 0.08 new IMI quarter-month. The IMI prevalence distribution showed a very similar but less striking skewed pattern. The IMI elimination rate distribution, on the other hand, was skewed, but was closer to the normal distribution with a very wide range of elimination rates and a less striking resemblance to the IMI prevalence distribution. Results from unconditional analyses are presented in Supplemental Table
S1 (available online: http://www.journalofdairyscience. $\operatorname{org} /)$.

\section{Effect of Incidence and Elimination Rates on IMI Prevalence}

Both incidence and elimination rates were significant predictors of the herd Staph. aureus IMI prevalence ( $P$ $\leq 0.05$ ). Scatter plots of the relationships between herd IMI prevalence and herd IMI incidence and elimination rates are presented in Figure 2. The herd incidence rate was the most important predictor of IMI prevalence: a reduction of the incidence rate equivalent to 

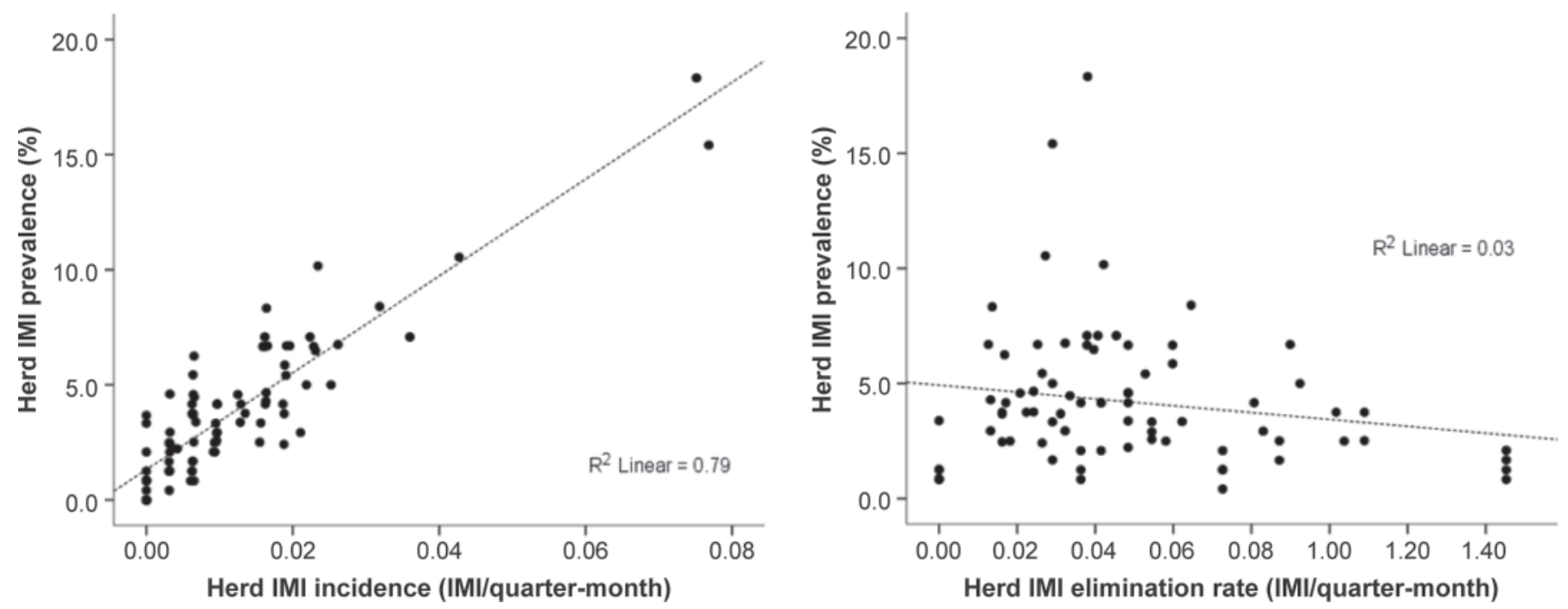

Figure 2. Scatter plots of herd Staphylococcus aureus IMI prevalence against herd IMI incidence and elimination rates.

its interquartile range (0.011 new IMI/quarter-month) was associated with a prevalence reduction of 2.2 percentage points; in comparison, an equivalent increase of the elimination rate by its interquartile range $(0.36$ eliminated IMI/quarter-month) resulted in a prevalence reduction of 0.4 percentage points.

\section{IMI Incidence}

The incidence data set comprised 37,919 pairs of milk samples at risk of becoming infected. These pairs were obtained from 15,337 quarters belonging to 3,911 different cows from the 90 studied herds. An incident Staph. aureus IMI was identified in 305 of the pairs at risk, yielding a mean incidence rate of 0.012 new Staph. aureus IMI per quarter-month (95\% CI: 0.011, 0.013). The herd IMI incidence distribution was right skewed with a large proportion of herds experiencing relatively low incidence (Figure 1). The median herd incidence was 0.007 new IMI per quarter-month. Bayesian conditional estimates of association for manageable risk factors that were significantly associated with odds of acquisition of a Staph. aureus IMI are presented in Table 2. The manageable risk factors retained were mainly milking procedures. Wearing gloves during milking and using premilking teat disinfection were associated with lower odds of acquiring a Staph. aureus IMI. Furthermore, the protective effect of wearing gloves was increased on uninfected quarters of cows that already had other Staph. aureus-infected quarters. Extreme callosity roughness and thickness of the teat end was associated with greater odds of IMI acquisition. The herd initial prevalence of Staph. aureus IMI was positively associated with the odds of a IMI acquisition.

\section{IMI Elimination}

The elimination data set comprised 958 pairs of milk samples. These were obtained from 586 quarters belonging to 437 different cows from 79 herds. Staphylococcus aureus was not cultured on the second sample of the pair for 264 of the 958 pairs, yielding a mean elimination rate of 0.39 eliminated Staph. aureus IMI per infected quarter-month (95\% CI: $0.35,0.43)$. The distribution of herd Staph. aureus IMI elimination rate was slightly right skewed around a median herd elimination rate of 0.39 eliminated IMI per quartermonth (Figure 1). Conditional estimates of association for manageable risk factors that were significantly associated with the odds of elimination of an existing Staph. aureus IMI obtained from the final models are presented in Table 3. Few manageable risk factors were significantly associated with Staph. aureus IMI elimination. Wearing gloves during milking was associated with higher odds of IMI elimination. The effect of stocking density on odds of IMI elimination was different for cows in the first $60 \mathrm{~d}$ of lactation compared with cows in a more advanced stage of lactation. Having a culling protocol where $>3$ clinical mastitis events are needed before culling a cow was associated with lower odds of IMI elimination compared with not having any defined culling protocol for clinical mastitis.

\section{IMI Prevalence}

To constitute the prevalence data set, 20,078 series of quarter milk samples were available. These series were obtained from 15,943 quarters belonging to 3,999 different cows in the 90 studied herds. Staphylococcus 
Table 2. Conditional estimates of association between manageable risk factors and odds of acquisition of a new Staphylococcus aureus IMI estimated in Bayesian hierarchical cross-classified models ${ }^{1}$

\begin{tabular}{|c|c|c|c|c|c|}
\hline Modeled manageable risk factor & $\beta$ & SE & $\mathrm{OR}^{2}$ & $95 \% \mathrm{CI}$ & Covariate $^{3}$ \\
\hline Cow with 0 Staph. aureus quarters & -0.849 & 0.263 & 0.43 & $0.26,0.72$ & quality, cow number of Staph. aureus \\
\hline Cow with 1 Staph. aureus quarter & 0.232 & 0.429 & 1.3 & $0.54,2.9$ & infected quarters on first sample, \\
\hline Cow with 3 Staph. aureus quarters & -3.474 & 1.710 & 0.03 & $0.01,0.89$ & \\
\hline Uses premilking teat disinfection & -0.533 & 0.232 & 0.59 & $0.37,0.92$ & - \\
\hline $\mathrm{N}$ & \multicolumn{4}{|c|}{ Referent } & \\
\hline $1 \mathrm{~A}$ & -0.124 & 0.274 & $0.88^{\mathrm{a}, \mathrm{b}}$ & $0.52,1.5$ & \\
\hline $1 \mathrm{~B}$ & -0.049 & 0.287 & $0.95^{\mathrm{a}, \mathrm{b}}$ & $0.54,1.7$ & \\
\hline $1 \mathrm{C}$ & 0.161 & 0.342 & $1.2^{\mathrm{a}, \mathrm{b}}$ & $0.60,2.3$ & \\
\hline $2 \mathrm{~A}$ & 0.151 & 0.308 & $1.2^{\mathrm{a}, \mathrm{b}}$ & $0.64,2.1$ & \\
\hline $2 \mathrm{~B}$ & 0.310 & 0.307 & $1.4^{\mathrm{a}, \mathrm{b}}$ & $0.75,2.5$ & \\
\hline $2 \mathrm{C}$ & 0.754 & 0.386 & $2.1^{\mathrm{a}, \mathrm{b}}$ & $1.0,4.5$ & \\
\hline Stall length & \multirow{2}{*}{\multicolumn{4}{|c|}{ Referent }} & - \\
\hline$<1.7 \mathrm{~m}$ & & & & & \\
\hline $1.7-1.8 \mathrm{~m}$ & 0.204 & 0.346 & $1.2^{\mathrm{a}}$ & $0.62,2.4$ & \\
\hline $1.8-1.9 \mathrm{~m}$ & 0.633 & 0.395 & $1.9^{\mathrm{a}}$ & $0.87,4.1$ & \\
\hline$>1.9 \mathrm{~m}$ & -1.009 & 0.531 & $0.36^{\mathrm{a}}$ & $0.13,1.0$ & \\
\hline Herd initial Staph. aureus quarter prevalence ${ }^{5}$ & 0.124 & 0.022 & 1.9 & $1.5,2.3$ & - \\
\hline
\end{tabular}

${ }^{1}$ Only statistically significant manageable risk factors (95\% CI not including the null value) are presented.

${ }^{2}$ For categorical variables with more than 2 classes, odds ratios (OR) with different superscripts differ (adjusted for multiple comparisons using the Bonferroni procedure). All the presented risk factors were significantly associated with the outcome, but in some cases, differences across levels of a risk factor could not be identified after correction for multiple comparisons.

${ }^{3}$ Covariates included in the model as confounders or effect modifiers to adjust the estimate of the manageable risk factor. Estimates of association are not reported for covariates, although they may have significantly differed from the null value.

${ }^{4}$ Teat-end condition score as proposed by Neijenhuis et al. (2000).

${ }^{5}$ Odds ratios and $95 \%$ CI for a $5 \%$ quarter prevalence difference.

Table 3. Conditional estimates of association between manageable risk factors and odds of elimination of an existing Staphylococcus aureus IMI estimated in Bayesian hierarchical cross-classified models ${ }^{1}$

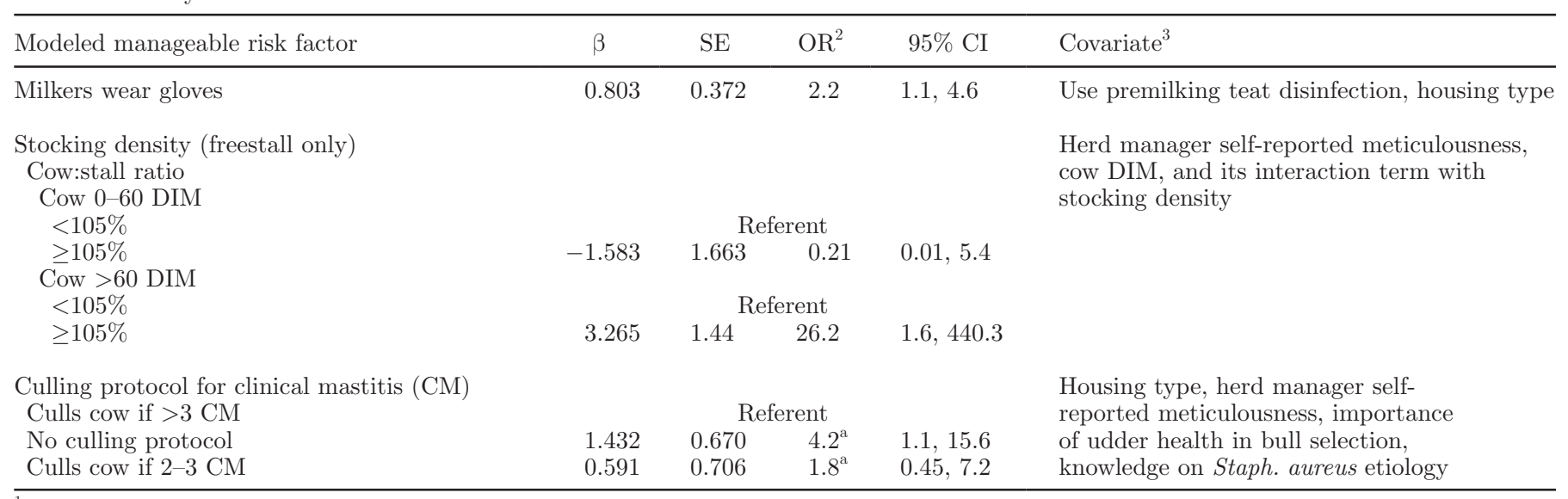

${ }^{1}$ Only statistically significant manageable risk factors (95\% CI not including the null value) are presented.

${ }^{2}$ For categorical variables with more than 2 classes, odds ratios (OR) with different superscripts differ (adjusted for multiple comparisons using the Bonferroni procedure). All the presented risk factors were significantly associated with the outcome, but in some cases, differences across levels of a risk factor could not be identified after correction for multiple comparisons.

${ }^{3}$ Covariates included in the model as confounders or effect modifiers to adjust the estimate of the manageable risk factor. Estimates of association are not reported for covariates, although they may have significantly differed from the null value. 
aureus was retrieved in at least one sample in 777 of these series, yielding a mean quarter prevalence of Staph. aureus of 3.9\% (95\% CI: 3.6, 4.2). The herd Staph. aureus IMI quarter prevalence distribution was right skewed with a median herd quarter prevalence of $3.3 \%$ and with a relatively small proportion of herds showing high prevalence of infection (Figure 1). Conditional estimates of association for manageable risk factors that were significantly associated with odds of a prevalent Staph. aureus IMI are presented in Table 4. Many manageable risk factors were associated with Staph. aureus IMI prevalence. Similar to the incidence models, wearing gloves, using premilking teat disinfection, and adequate teat-end condition were all associated with lower IMI prevalence. Higher odds of having a prevalent Staph. aureus IMI were observed in herds in which the vacuum level was checked daily. Measuring milk conductivity during milking was associated with higher IMI prevalence in herds housed in freestalls. Many housing variables were associated with IMI prevalence, but, for many of them, the association observed was modulated by the cow's parity. For instance, the type of stall base was not significantly associated with IMI prevalence in first-parity cows. Stalls filled with sand or made of concrete were associated with lower IMI prevalence in older cows (greater than first parity) compared with stalls covered with a mattress or rubber mat. Similarly, using a depth of bedding $\geq 2 \mathrm{~cm}$ and longer stalls $(>1.9 \mathrm{~m})$ were both associated with lower IMI prevalence in older cows (greater than third parity). Having a greater number of maternity pens on the farm was associated with lower odds of having a prevalent Staph. aureus IMI. Having a culling protocol for clinical mastitis requiring $>3$ clinical mastitis events in a lactation before a culling decision is taken was associated with higher IMI prevalence compared with not having any culling protocol for clinical mastitis. Finally, in herds where a veterinarian was not consulted regularly for udder health issues, clinical mastitis treatment duration of more than $2 \mathrm{~d}$ was associated with lower IMI prevalence.

\section{DISCUSSION}

This is the first study reporting Staph. aureus lactational IMI incidence rate, elimination rate, and risk factors associated with acquisition and elimination of these IMI in a large sample of herds over such a long period. Intramammary infection incidence and elimination rates are the main determinants of herd IMI prevalence and give better insight into the dynamic of IMI within a herd than IMI prevalence alone. In our study, quarter Staph. aureus IMI prevalence was variable between herds (range: 0 to 18.3\%). Other recent studies on Staph. aureus IMI prevalence have observed important herd prevalence variation, with herd quarter prevalence ranging from 0 to $40.3 \%$ in Belgium (Piepers et al., 2007) and from 0 to $18.6 \%$ in Switzerland (Moret-Stalder et al., 2009). With such a range of quarter prevalence between herds, a similar variation in herd incidence and elimination rates of Staph. aureus IMI was expected. The shape of the distribution of herd IMI incidence, still, was quite revealing. In this study, most dairy herds were very efficient at preventing acquisition of new Staph. aureus IMI; only a minority of herds experienced an IMI incidence $>0.02$ new IMI/ quarter-month (Figure 1). Furthermore, as expected for a chronic type of IMI such as that caused by Staph. aureus, the rate of acquisition of new IMI had a much greater effect on IMI prevalence than the elimination rate; hence the need to identify the manageable risk factors associated with IMI incidence to decrease prevalence of Staph. aureus IMI.

\section{Manageable Risk Factors}

To fully demonstrate the web of relationship between the manageable risk factors identified and the 3 outcomes studied, a conceptual chart of these associations based on results obtained from the conditional analyses is presented in Figure 3. Similar to previously published studies on IMI prevalence, numerous manageable risk factors were significantly associated with odds of having a prevalent Staph. aureus IMI. It is important to realize, however, that these risk factors can only modulate IMI prevalence through their effects on IMI incidence or elimination. For this reason, less consideration should be given to variables associated solely with IMI prevalence. The results presented in Tables 2, 3, and 4 should instead be interpreted as a whole using the conceptual chart presented in Figure 3, and more weight should be given to variables associated with many of the outcomes. Among these, having milkers wear gloves during milking was the only risk factor identified in this study that showed a desirable association with all 3 outcomes. Interestingly, the protective association between wearing gloves and incidence of IMI seemed to improve as the number of already infected quarters on a cow increased. This improvement was, however, limited to the relatively low proportion of uninfected quarters belonging to cows with 2 or 3 already infected quarters and could have been modulated by a third extraneous variable or have occurred by chance alone. Previous studies have shown that transmission of Staph. aureus IMI can arise from infected herd mates but also from infected quarters on the same cow and that these 2 processes operate on different scales (Zadoks et al., 2001; Østerås et al., 2006). In this study, wearing gloves 
Table 4. Conditional estimates of association between manageable risk factors and odds of a prevalent Staphylococcus aureus IMI estimated in Bayesian hierarchical cross-classified models ${ }^{1}$

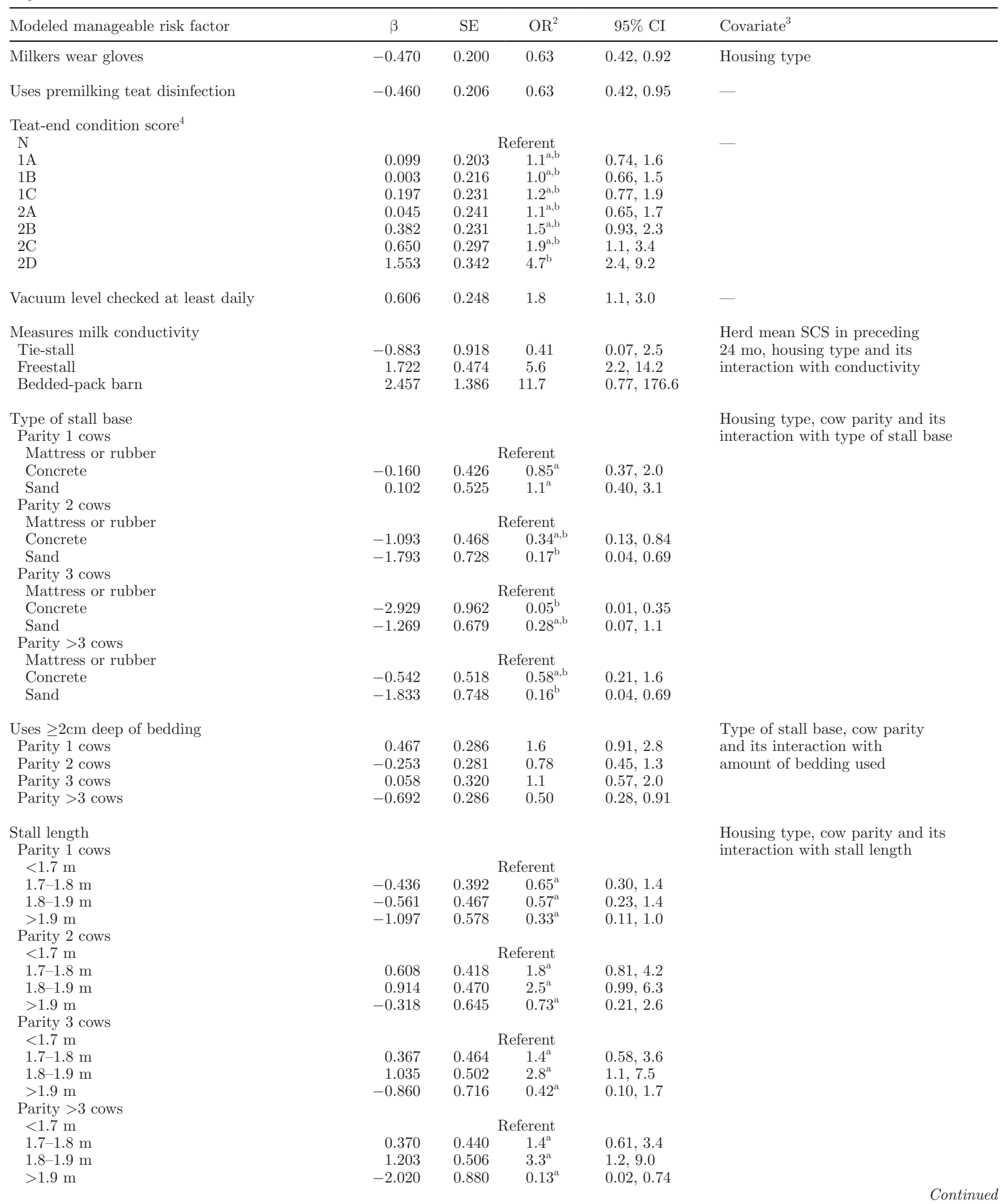


Table 4 (Continued). Conditional estimates of association between manageable risk factors and odds of a prevalent Staphylococcus aureus IMI estimated in Bayesian hierarchical cross-classified models ${ }^{1}$

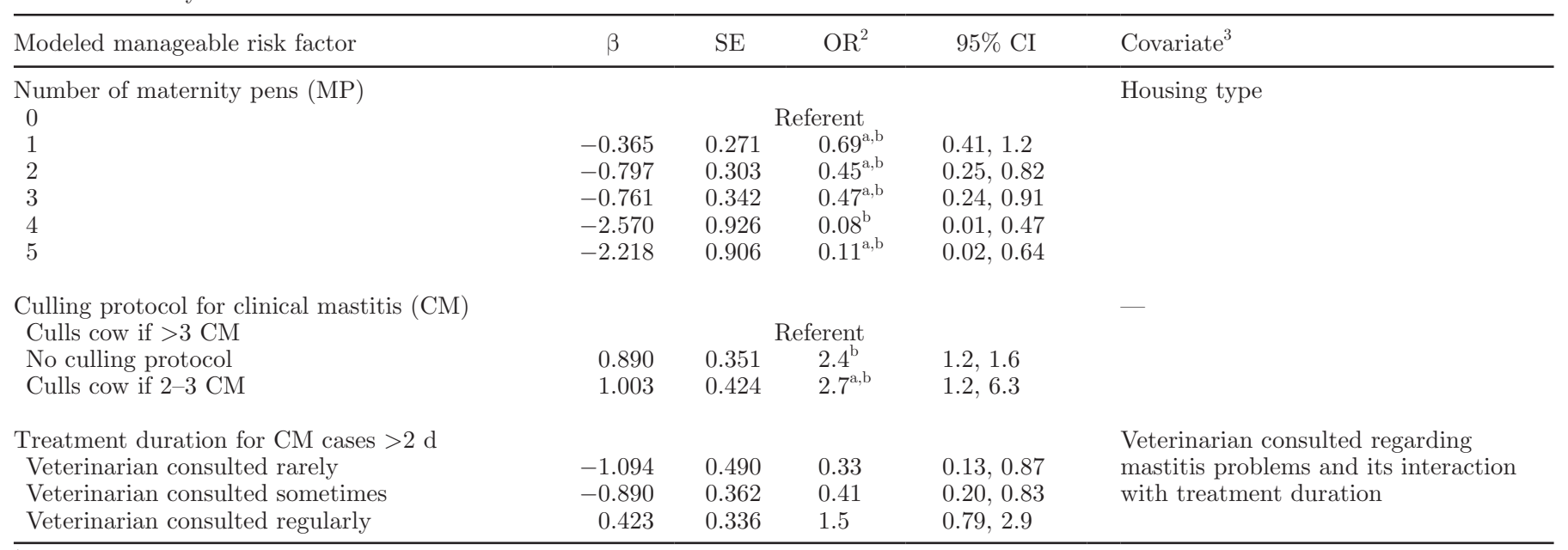

${ }^{1}$ Only statistically significant manageable risk factors (95\% CI not including the null value) are presented.

${ }^{2}$ For categorical variables with more than 2 classes, odds ratios (OR) with different superscripts differ (adjusted for multiple comparisons using the Bonferroni procedure). All the presented risk factors were significantly associated with the outcome, but in some cases, differences across levels of a risk factor could not be identified after correction for multiple comparisons.

${ }^{3}$ Covariates included in the model as confounders or effect modifiers to adjust the estimate of the manageable risk factor. Estimates of association are not reported for covariates, although they may have significantly differed from the null value.

${ }^{4}$ Teat-end condition score as proposed by Neijenhuis et al. (2000).

during milking seemed to be an efficient technique to prevent IMI transmission from infected herd mates, as can be concluded from the significantly lower odds of IMI acquisition observed for quarters of cows without any Staph. aureus-infected quarters. In addition, wearing gloves seemed to prevent transmission of IMI from other infected quarters of the same cow, as can be seen from the generally decreasing odds of IMI acquisition associated with wearing gloves as the number of infected quarter on a cow increases. Although wearing gloves is a commonly recommended practice and has been found, in a recent literature review, to be consistently associated with lower SCC (Dufour et al., 2011), little evidence exists of the exact mechanisms through which gloves may limit transmission of contagious infections. Wearing gloves during milking is traditionally recommended in part to prevent colonization of milkers' hands with transient flora such as Staph. aureus, and, therefore, to prevent subsequent transmission to uninfected quarters. Evidence that colonization with Staph. aureus of the skin of gloved hands does occur (Doebbeling et al., 1988), however, casts doubt on the rationale behind this principle. In addition, the finding that the preventive effect of wearing gloves increases as the number of already infected quarters of a cow increases, as observed here, can hardly be explained by this underlying principle. On the other hand, Olde Riekerink et al. (2008b) found that lower bacterial counts were retrieved on gloved hands compared with bare hands after milking. It seems plausible, therefore, that the physical properties of gloves are an important limiting factor for bacteria adhesion, and that wearing them might greatly reduce the potential role of milkers' hands as vector for transmission of Staph. aureus IMI. Finally, having milkers wearing gloves could increase their awareness toward hand hygiene in general and, hence, reduce the amount of bacteria presented to the teat end.

In this study, wearing gloves during milking was also associated with higher odds of elimination of an existing Staph. aureus IMI. We speculate that wearing gloves during milking might have efficiently restricted the transmission of contagious, host-adapted, and persistent strains of Staph. aureus in these herds. The strains found in these herds may, therefore, have originated in a greater proportion from nonmammary sites and were possibly less well adapted to the mammary gland, explaining their higher elimination rate. Previous studies have reported the relatively important genetic variability between Staph. aureus isolates retrieved in a given herd (Zadoks et al., 2000; Middleton et al., 2002). A certain variability between herds in the number of different strains present has also been reported and has been associated with specific management practices (Middleton et al., 2002). In addition, Roberson et al. (1994) demonstrated that Staph. aureus appears to be omnipresent in the environment of cows, and that the environment could be a potential source of Staph. aureus IMI. The association between gloves and odds of eliminating an existing IMI could be mediated by 


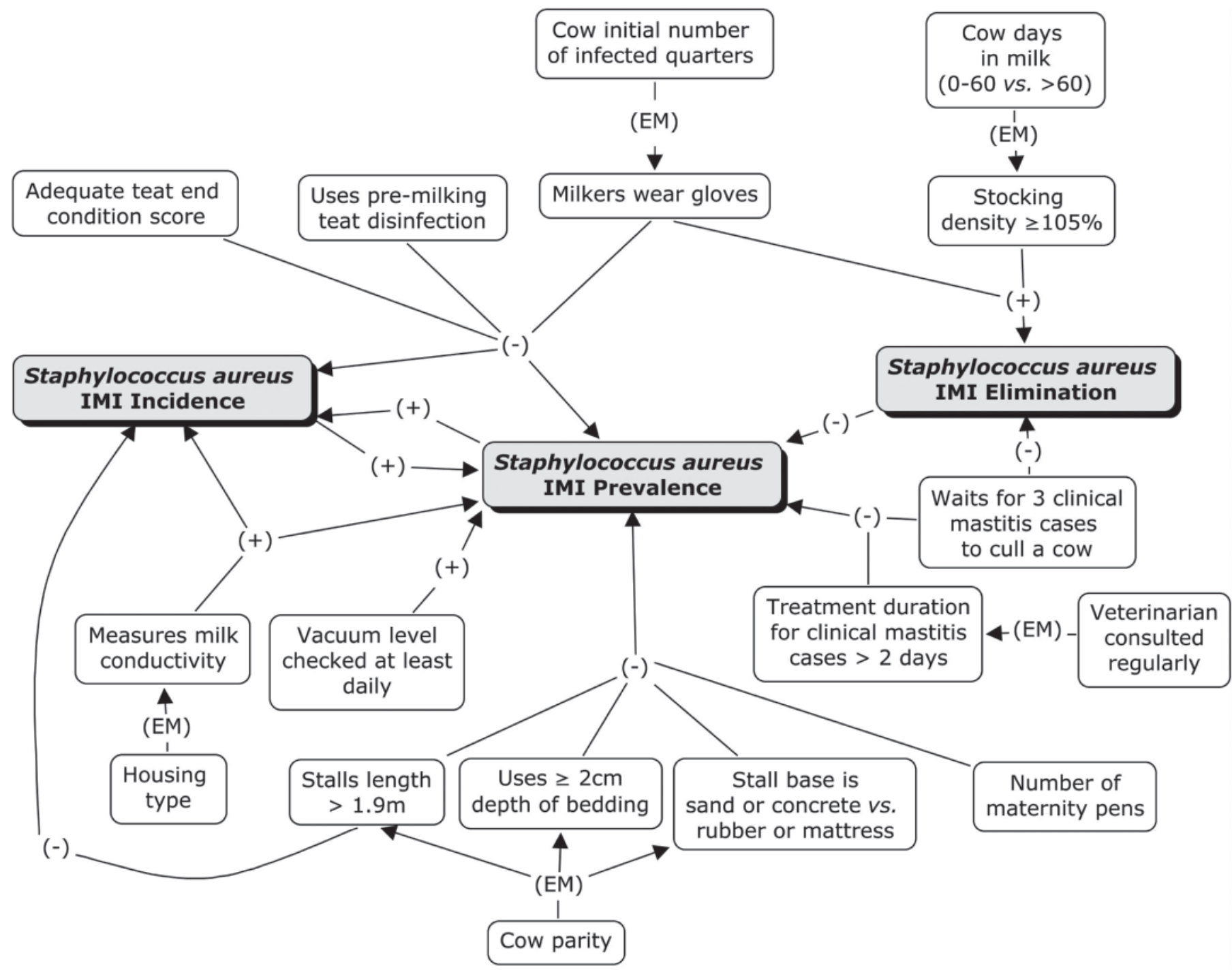

$(-)$ :Associated with lower Staph aureus IMI incidence, elimination, or prevalence $(+)$ : Associated with higher Staph aureus IMI incidence, elimination, or prevalence (EM): Effect modifier

Figure 3. Conceptual chart of associations between manageable risk factors and Staphylococcus aureus IMI incidence, elimination, and prevalence.

the initial differential selection of Staph. aureus strains causing IMI rather than by any authentic increased cure rate. Nevertheless, the significant associations seen with all 3 IMI outcomes in this study, and with IMI prevalence in many previous studies, indicate that wearing gloves during milking is a crucial component of any Staph. aureus control program.

Similarly, using premilking teat disinfection was associated with lower Staph. aureus IMI incidence and prevalence. Premilking teat disinfection is usually recommended as a means to prevent environmental IMI (Nickerson and Boddie, 1997). Oliver et al. (1993), however, previously reported lower incidence of Staph. aureus IMI on quarters where teats were predipped and postdipped compared with quarters where teats were only postdipped. In addition, Piccinini et al. (2009) observed that some Staph. aureus strains were isolated both from the teat skin of cows and from milk of infected quarters, highlighting the possible role of teat-skin contamination and, by extension, of teat-skin disinfection in Staph. aureus IMI epidemiology.

In this study, increasing callosity and roughness of the teat end were generally associated with higher odds of IMI acquisition and, consequently, with higher IMI 
prevalence. The healthy teat end serves as the primary barrier hindering bacterial penetration into the mammary gland. Teat-end lesions and callosity have been associated with higher prevalence of subclinical mastitis (Sieber and Farnsworth, 1981) and higher incidence of clinical mastitis (Neijenhuis et al., 2001). The development of a small amount of teat-end callosity can be seen as a normal physiological and desirable adaptation that follows initiation of milking; the building of an extremely thick or rough callosity, on the other hand, can impair teat sphincter function and favor penetration of bacteria into the mammary gland. Prolonged milking time and practices resulting in extended milking duration have been associated with increased degree of lesions and increased teat-end callosity roughness (Farnsworth, 1995; Neijenhuis et al., 2000). Having proper teat stimulation, an appropriate lag time between teat stimulation and milking unit attachment, and using well-adjusted automatic take-offs are all key conditions that can reduce milking duration and prevent the formation of extreme callosity, thereby potentially reducing Staph. aureus IMI incidence. In the present study, however, measurements of the function of the milking system and of milking procedure timeliness were not captured; therefore, a direct link between IMI incidence and these important parts of the milking procedures could not be made.

Measuring milk conductivity to detect cows suffering from clinical mastitis was associated, in this study, with higher incidence and prevalence of Staph. aureus IMI. This practice was used in only 6 of the participating herds, 1 herd housed in tie-stalls, 1 in a bedded-pack, and 4 herds in freestalls, and was associated with higher odds of IMI acquisition in general and with higher odds of having a prevalent IMI in herds where a freestall system was used. The associations observed between this practice and Staph. aureus IMI outcomes are likely consequences of another latent unmeasured concept rather than causal associations (residual confounding). For instance, dairy producers with specific attitudes, motivations, or knowledge might be more inclined to adopt such technology and these social traits have been shown to be associated with IMI epidemiology (Jansen and Borne, 2008). Although none of the social traits measured in this study could be identified as important confounders of this association, we must note that the social trait measurements were shown to carry a relatively high level of measurement error (Dufour et al., 2010). Although practices used on farm are likely to remain relatively constant over time, attitudes, motivations, and knowledge tend to vary and evolve from day to day. Any adjustment for these imperfectly measured confounders would then be an incomplete or inadequate adjustment.
Similarly, higher odds of having a prevalent Staph. aureus IMI were observed on farms where dairy producers verified the vacuum level of the milking system at least daily. Again, the observed association could result from residual confounding by social traits or any other unmeasured or imperfectly measured factor. In this case, though, the only significant association was with prevalence of infection and, like numerous prevalence studies before this one, a reverse order of causation cannot be ruled out. In fact, it is probable that dairy producers who have a high prevalence of Staph. aureus IMI and are aware of that fact might be more inclined to increase their level of surveillance of the milking system rather than the other way around. The observed association illustrates an important issue that needs to be dealt with when analyzing prevalence data arising from cross-sectional study designs.

The herd prevalence of Staph. aureus IMI at the beginning of a sampling period showed a strong positive association with the subsequent odds of acquisition of an IMI. For each $5 \%$ increase in the herd proportion of Staph. aureus-infected quarters, the odds of subsequent IMI acquisition were increased 2-fold (Table 2). Furthermore, uninfected quarters from cows having 1, 2, or 3 already infected quarters had respectively $4.5,6.8$, and 15.8 higher odds of becoming infected compared with quarters from cows without any infected quarters (Table S1, online-only supplementary material; available at http://www.journalofdairyscience.org/). Similar to the work of Middleton et al. (2001), these results suggest that, in herds experiencing a relatively high prevalence of Staph. aureus IMI, reducing the pool of infection through culling, permanently drying off, or successfully treating infected cows or quarters may, in some situations, be an important step to control the subsequent rate of acquisition of new IMI. In these herds, a reduction of the pool of infected quarters, coupled with other measures aimed at preventing transmission of IMI from infected to uninfected quarters, would be required to match the infectious pressure power from the collection of infected quarters. The full benefit from culling infected cows or drying off infected quarters, however, is lost if the time between the initial infection of a quarter and the subsequent culling or drying decision is too long (White et al., 2006). This difficulty would limit the practicality of this control measure in some herds. In addition, in herds with moderate to low prevalence of IMI, although an initial prevalence reduction may reduce the subsequent incidence, it may not be the most economical option.

Although Staph. aureus is mainly recognized as a contagious pathogen that can be transmitted during milking, many housing-related variables were associated with IMI prevalence. Again, because almost all of 
these variables were associated strictly with the prevalence outcome, the credibility of these results should be questioned. Nevertheless, these housing variables could have an effect on IMI prevalence by altering the cow's defenses against infection, increasing or decreasing contact between bacteria and the teat end, or promoting or reducing the growth of specific strains of Staph. aureus in the environment of the cow. A noteworthy observation is that the effect of most housing variables varied depending on the cow's characteristics, primarily parity but also DIM (see Figure 3). This seems to underscore the important effect of the interface between host and environment in IMI epidemiology and, more precisely, of the adaptation capability, or lack thereof, of specific groups of cows to their environment. The associations observed could, therefore, be mediated rather by an alteration of the cow's immune defenses. These fragile observations should be further investigated and, if confirmed, would support the design of housing conditions specific to particular groups of cows, so that the environment is adapted to the cow rather than the reverse. These results suggest, for instance, that older cows in particular could benefit from the increased comfort provided by longer and more comfortable stalls.

Increasing the number of maternity pens was associated with lower odds of having a prevalent Staph. aureus IMI. Cows usually spent a limited amount of time in a maternity pen at the beginning of the milking period, and most cows followed in this study had already joined the regular milking herd when first sampled. Maternity pen variables, therefore, were not tested as possible risk factors for incidence or elimination of IMI during the milking period because cows were no longer exposed to these factors. Nevertheless, the early milking period is recognized as a period of tremendous importance for acquisition of new IMI. To better understand the association observed between number of maternity pens used and IMI prevalence during the milking period, studies specifically evaluating the effect of housing around calving time on the incidence of IMI during the early lactation should be conducted. Such studies could shed light on some of the results obtained from those already conducted on risk factors associated with prevalence of IMI during early lactation (Svensson et al., 2006; Nyman et al., 2009).

In freestall housing systems, having a cow:stall ratio $\geq 105 \%$ was associated with lower odds of eliminating an existing IMI in early lactation (1 to 60 DIM) followed by statistically significantly increased odds of elimination for cows $>60$ DIM. The number of observations available to obtain this estimate, however, was limited, resulting in a large confidence interval around the estimate. One of the generally recognized consequences of overstocking is a reduction in the cow's immune function through increased stress caused by competition for stalls and feed bunk access (Huzzey et al., 2006; Fregonesi et al., 2007). It is possible that during the early lactation period, the increased stress caused by overstocking would further compromise the already depressed immune functions of the cow, leading to acquisition of IMI that are not necessarily well hostadapted and that are less persistent. As the immune system of the cow returns to normal later in lactation, these less persistent IMI would easily be eliminated, explaining the observed increased elimination rate.

Finally, management of clinical mastitis cases was associated with some Staph. aureus IMI outcomes. In herds where the veterinarian was not consulted regularly concerning mastitis problems, longer treatment duration $(>2 \mathrm{~d})$ for clinical mastitis cases was associated with lower odds of having a prevalent IMI. Researchers have reported higher cure rate of both subclinical and clinical Staph. aureus mastitis with a longer treatment period (Barkema et al., 2006). This association, however, might also be indicative of the effect of the dairy producer's motivations and attitudes toward mastitis rather than a true effect of treatment duration. In fact, producers who treated clinical mastitis cases for longer may have had a more conscientious attitude toward mastitis in general and be more motivated to improve udder health in their herds. In addition to treatment duration, choice of culling protocols regarding cows with multiple clinical mastitis episodes in a given lactation showed conflicting associations with Staph. aureus prevalence and elimination rate. As expected, odds of eliminating a Staph. aureus IMI were lower for dairy producers waiting for more than 3 clinical mastitis episodes before culling a cow, suggesting that this practice can lead to persistent IMI. Alternatively, odds of having a prevalent Staph. aureus IMI were lower in these herds. Again, care must be taken when interpreting prevalence data, as the explanation for the association observed could well be that dairy producers who had a low herd Staph. aureus IMI prevalence did not need to use a strict clinical mastitis culling protocol, rather than the other way around.

In this study, some of the practices that have been recommended for years in mastitis control programs such as universal dry-cow therapy and postmilking teat disinfection were not significantly associated with any of the 3 outcomes studied. It is important to note, however, that these practices were widely adopted by the participating herds; $88 \%$ of the herds used universal dry-cow therapy and 99\% used postmilking teat disinfection. The power to identify a significant association between these practices and our IMI outcomes was therefore quite low. These practices have shown very desirable and consistent associations with udder health 
in general (Dufour et al., 2011) and should, therefore, not be ruled out of mastitis control programs based on results from this specific study. The practices identified in this study should instead be considered as practices that could potentially further improve the udder health situation in herds where postmilking teat disinfection and blanket dry-cow therapy have already been implemented.

\section{Potential Biases}

As in all previously published udder health studies, many potential biases might be operating in this study and may have influenced the observed results. First, herds selected to participate in this study were not a random sample of Canadian dairy herds. Efforts were made to recruit a selection of herds that would be as representative as possible of the Canadian dairy industry, and a comparison of the selected herds from this cohort with Canadian herds conducted by Reyher et al. (2011) suggested that selection was valid in terms of number of milking cows, milk production, type of housing system used, and geometric and arithmetic SCC averages. Nevertheless, as discussed in Dufour et al. (2010), the dairy producers volunteering for such a study might be more progressive and the management practices used on their farms might differ from those of other Canadian dairy farms. In addition, regular visits by a team of technicians and researchers might have promoted the use of some management practices by the NCDF producers. Any resulting bias would most likely be reflected in the estimates of incidence and elimination rates, of prevalence, and of the proportion of herds using specific management practices. This bias would be much less likely to adversely affect the observed relationships between risk factors and outcomes of interest.

Second, although attempts to adjust for the most important confounders were made, it is likely that some residual confounding may still bias the observed results to some extent. This residual confounding could arise from unknown unmeasured confounders and from imperfectly measured confounders. With an important confounder being ignored, reverse causality may have occurred despite the care taken to ensure the logical temporal relationships between variables. The direction of bias caused by this lack of adjustment is unpredictable. The magnitude of these biases, however, is probably relatively small. Numerous studies related to udder health and to Staph. aureus in Canada and in other parts of the world have been conducted in the last few decades, and it is very unlikely that a strong confounder of the association between practices used on farm and Staph. aureus IMI would not have been identified before. Similarly, adjustment of an association with an imperfectly measured confounder such as dairy producers' attitudes and motivations would provide an incomplete but still significant adjustment.

Finally, and most importantly, none of the outcomes assessed or factors evaluated were free of measurement error. For instance, Staph. aureus-infected quarters were identified using routine bacteriological culture, which is known to have imperfect sensitivity (Dohoo et al., 2011). It might be assumed that these measurement errors probably occur randomly (nondifferential). Under this assumption, the resulting bias direction is predictable and toward the null value, and the associations reported are therefore not as extreme as the true associations. The major effect of this bias, therefore, would be a reduction of power of the study. Fortunately, with the high reported sensitivity of Staph. aureus bacteriological culture (90\%) and specificity of almost 100\% (Dohoo et al., 2011), the magnitude of this bias would be relatively small. In this study, in addition to misclassified outcomes, a certain level of exposure and covariate misclassification has been reported (Dufour et al., 2010). As with outcome misclassification, under the assumption of nondifferential exposure misclassification, a predictable bias toward the null would be expected. Covariate misclassification would reduce the ability to remove confounding effects and, as noted above, this bias might be in either direction, but would likely have been quite small. Overall, it is likely that measurement error biases would have biased observed results toward the null, so the true effect of factors evaluated are likely to be greater than those reported in this article.

\section{CONCLUSIONS}

Preventing acquisition of new Staph. aureus IMI seems to be the key determinant in control of Staph. aureus IMI prevalence. In herds where postmilking teat disinfection and blanket dry-cow therapy have already been implemented, many additional practices can be used to further modulate IMI incidence; most of these practices are related to milking procedures. In herds that have a very high prevalence of Staph. aureus IMI, a first-round reduction of the number of infected quarters might be needed to complement measures aimed at preventing new IMI acquisition.

\section{ACKNOWLEDGMENTS}

The authors thank all of the dairy producers and animal health technicians who participated in this study. This research was financed by the Natural Sciences and Engineering Research Council of Canada (Ottawa, ON, Canada), Alberta Milk (Edmonton, AB, Canada), 
Dairy Farmers of New Brunswick (Roachville, NB, Canada), Dairy Farmers of Nova Scotia (Lower Truro, NS, Canada), Dairy Farmers of Ontario (Mississauga, ON, Canada), Dairy Farmers of Prince Edward Island (Charlottetown, PE, Canada), Novalait Inc. (Québec, QC, Canada), Dairy Farmers of Canada (Ottawa, ON, Canada), Canadian Dairy Network (Guelph, ON, Canada), Agriculture and Agri-Food Canada (Ottawa, ON, Canada), Public Health Agency of Canada (Ottawa, ON, Canada), Technology PEI Inc. (Charlottetown, PE, Canada), Université de Montréal (Montréal, QC, Canada), and University of Prince Edward Island (Charlotteown, PE, Canada), through the Canadian Bovine Mastitis Research Network (St-Hyacinthe, QC, Canada). The first author (Dufour) was the lead author of this manuscript and was responsible along with the second (Dohoo) and last author (Scholl) for the realization of the project. The other authors were responsible for the recruitment and follow-up of the NCDF cohort and the data collection and contributed to the design of the study and analyses. All authors were involved in reviewing the manuscript.

\section{REFERENCES}

Barkema, H. W., Y. H. Schukken, T. J. Lam, M. L. Beiboer, H. Wilmink, G. Benedictus, and A. Brand. 1998. Incidence of clinical mastitis in dairy herds grouped in three categories by bulk milk somatic cell counts. J. Dairy Sci. 81:411-419.

Barkema, H. W., Y. H. Schukken, and R. N. Zadoks. 2006. Invited review: The role of cow, pathogen, and treatment regimen in the therapeutic success of bovine Staphylococcus aureus mastitis. J. Dairy Sci. 89:1877-1895.

Brenner, H., and M. Blettner. 1997. Controlling for continuous confounders in epidemiologic research. Epidemiology 8:429-434.

Diez-Roux, A. V. 1998. Bringing context back into epidemiology: Variables and fallacies in multilevel analysis. Am. J. Public Health 88:216-222.

Djabri, B., N. Bareille, F. Beaudeau, and H. Seegers. 2002. Quarter milk somatic cell count in infected dairy cows: A meta-analysis. Vet. Res. 33:335-357.

Doebbeling, B. N., M. A. Pfaller, A. K. Houston, and R. P. Wenzel. 1988. Removal of nosocomial pathogens from the contaminated glove. Ann. Intern. Med. 109:394-398.

Dohoo, I., W. Martin, and H. Stryhn. 2003. Veterinary Epidemiologic Research. AVC Inc., Charlottetown, PEI, Canada.

Dohoo, I. R., J. Smith, S. Andersen, D. F. Kelton, and S. Godden. 2011. Diagnosing intramammary infections: Evaluation of definitions based on a single milk sample. J. Dairy Sci. 94:250-261.

Dufour, S., H. W. Barkema, L. DesCôteaux, T. J. DeVries, I. R. Dohoo, K. Reyher, J. P. Roy, and D. T. Scholl. 2010. Development and validation of a bilingual questionnaire for measuring udder health related management practices on dairy farms. Prev. Vet. Med. 95:74-85.

Dufour, S., A. Frechette, H. W. Barkema, A. Mussell, and D. T. Scholl. 2011. Invited review: Effect of udder health management practices on herd somatic cell count. J. Dairy Sci. 94:563-579.

Farnsworth, R. J. 1995. Observations on teat lesions. Pages 28-33 in Proc. Minnesota Dairy Health Conf. University of Minnesota, Minneapolis.

Fregonesi, J. A., C. B. Tucker, and D. M. Weary. 2007. Overstocking reduces lying time in dairy cows. J. Dairy Sci. 90:3349-3354.
Höfler, M. 2005. The effect of misclassification on the estimation of association: A review. Int. J. Methods Psychiatr. Res. 14:92-101.

Hogan, J. S., R. N. Gonzalez, R. J. Harmon, S. C. Nickerson, S. P. Oliver, J. W. Pankey, and K. L. Smith. 1999. Laboratory Handbook on Bovine Mastitis. National Mastitis Council, Madison, WI.

Huzzey, J. M., T. J. DeVries, P. Valois, and M. A. von Keyserlingk. 2006. Stocking density and feed barrier design affect the feeding and social behavior of dairy cattle. J. Dairy Sci. 89:126-133.

Jansen, J., and B. H. P. Borne. 2008. Mastitis incidence explained by farmers' attitude and behaviour. Pages 117-130 in Proc. Ann. Conf. Soc. Vet. Epidemiol. Prev. Med. Wageningen UR, Liverpool, UK.

Mickey, R. M., and S. Greenland. 1989. The impact of confounder selection criteria on effect estimation. Am. J. Epidemiol. 129:125137.

Middleton, J. R., L. K. Fox, J. M. Gay, J. W. Tyler, and T. E. Besser. 2002. Use of pulsed-field gel electrophoresis for detecting differences in Staphylococcus aureus strain populations between dairy herds with different cattle importation practices. Epidemiol. Infect. 129:387-395.

Middleton, J. R., L. K. Fox, and T. H. Smith. 2001. Management strategies to decrease the prevalence of mastitis caused by one strain of Staphylococcus aureus in a dairy herd. J. Am. Vet. Med. Assoc. 218:1581-1612, 1615-1618.

Moret-Stalder, S., C. Fournier, R. Miserez, S. Albini, M. G. Doherr, M. Reist, W. Schaeren, M. Kirchhofer, H. U. Graber, A. Steiner, and T. Kaufmann. 2009. Prevalence study of Staphylococcus aureus in quarter milk samples of dairy cows in the Canton of Bern, Switzerland. Prev. Vet. Med. 88:72-76.

Neijenhuis, F., H. W. Barkema, H. Hogeveen, and J. P. Noordhuizen. 2000. Classification and longitudinal examination of callused teat ends in dairy cows. J. Dairy Sci. 83:2795-2804.

Neijenhuis, F., H. W. Barkema, H. Hogeveen, and J. P. Noordhuizen. 2001. Relationship between teat-end callosity and occurrence of clinical mastitis. J. Dairy Sci. 84:2664-2672.

Nickerson, S. C., and R. L. Boddie. 1997. Mastitis prevention: An overview of pre- and postmilking teat antisepsis research. Louisiana Agric. 40:24-25.

Nyman, A. K., U. Emanuelson, A. H. Gustafsson, and K. Persson Waller. 2009. Management practices associated with udder health of first-parity dairy cows in early lactation. Prev. Vet. Med. 88:138-149.

Olde Riekerink, R. G., H. W. Barkema, D. F. Kelton, and D. T. Scholl. 2008a. Incidence rate of clinical mastitis on Canadian dairy farms. J. Dairy Sci. 91:1366-1377.

Olde Riekerink, R. G., H. W. Barkema, D. T. Scholl, D. E. Poole, and D. F. Kelton. 2010. Management practices associated with the bulk-milk prevalence of Staphylococcus aureus in Canadian dairy farms. Prev. Vet. Med. 97:20-28.

Olde Riekerink, R. G., O. C. Sampimon, V. J. Eerland, M. J. Swarts, and T. J. G. M. Lam. 2008b. Comparing bacterial counts on bare hands with gloved hands during milking. Pages 77-82 in Proc. Int. Conf. Mastitis Contr. Wageningen Academic Publishers, Wageningen, the Netherlands.

Oliver, S. P., M. J. Lewis, T. L. Ingle, B. E. Gillespie, and K. R. Matthews. 1993. Prevention of bovine mastitis by a premilking teat disinfectant containing chlorous acid and chlorine dioxide. J. Dairy Sci. 76:287-292

Østerås, O., L. Sølverød, and O. Reksen. 2006. Milk culture results in a large Norwegian survey - Effects of season, parity, days in milk, resistance, and clustering. J. Dairy Sci. 89:1010-1023.

Piccinini, R., L. Cesaris, V. Dapra, V. Borromeo, C. Picozzi, C. Secchi, and A. Zecconi. 2009. The role of teat skin contamination in the epidemiology of Staphylococcus aureus intramammary infections. J. Dairy Res. 76:36-41.

Piepers, S., L. De Meulemeester, A. de Kruif, G. Opsomer, H. W. Barkema, and S. De Vliegher. 2007. Prevalence and distribution of mastitis pathogens in subclinically infected dairy cows in Flanders, Belgium. J. Dairy Res. 74:478-483.

Raftery, A. E., and S. M. Lewis. 1992. How many iterations in the Gibbs Sampler? Pages 763-773 in Bayesian Statistics 4. J. M. Ber- 
nardo, J. O. Berger, A. P. Dawid, and A. F. M. Smith, ed. Oxford University Press USA, New York, NY.

Reyher, K. K., S. Dufour, H. W. Barkema, L. DesCôteaux, T. J. Devries, I. R. Dohoo, G. P. Keefe, J. P. Roy, and D. T. Scholl. 2011. The National Cohort of Dairy Farms - A data collection platform for mastitis research in Canada. J. Dairy Sci. 94:1616-1626.

Roberson, J. R., L. K. Fox, D. D. Hancock, J. M. Gay, and T. E Besser. 1994. Ecology of Staphylococcus aureus isolated from various sites on dairy farms. J. Dairy Sci. 77:3354-3364.

Rothman, K. J., S. Greenland, and T. L. Lash. 2008. Modern Epidemiology. Lippincott, Williams \& Wilkins, Philadelphia, PA.

Sampimon, O., H. W. Barkema, I. Berends, J. Sol, and T. Lam. 2009 Prevalence of intramammary infection in Dutch dairy herds. J. Dairy Res. 76:129-136.

Sieber, R. L., and R. J. Farnsworth. 1981. Prevalence of chronic teatend lesions and their relationship to intramammary infection in 22 herds of dairy cattle. J. Am. Vet. Med. Assoc. 178:1263-1267.

Svensson, C., A. K. Nyman, K. Persson Waller, and U. Emanuelson. 2006. Effects of housing, management, and health of dairy heifers on first-lactation udder health in southwest Sweden. J. Dairy Sci. 89:1990-1999.

USDA-APHIS. 2008. Prevalence of contagious mastitis pathogens on US dairy operations, 2007. APHIS Veterinary Services Info Sheet. \#N533.1008. APHIS, USDA, Washington, DC.
White, L. J., T. J. Lam, Y. H. Schukken, L. E. Green, G. F. Medley and M. J. Chappell. 2006. The transmission and control of mastitis in dairy cows: A theoretical approach. Prev. Vet. Med. 74:67-83.

Wilson, D. J., R. N. Gonzalez, and H. H. Das. 1997. Bovine mastitis pathogens in New York and Pennsylvania: Prevalence and effects on somatic cell count and milk production. J. Dairy Sci 80:2592-2598

Zadoks, R., W. van Leeuwen, H. Barkema, O. Sampimon, H. Verbrugh, Y. H. Schukken, and A. van Belkum. 2000. Application of pulsed-field gel electrophoresis and binary typing as tools in veterinary clinical microbiology and molecular epidemiologic analysis of bovine and human Staphylococcus aureus isolates. J. Clin. Microbiol. 38:1931-1939.

Zadoks, R. N., H. G. Allore, H. W. Barkema, O. C. Sampimon, G. J. Wellenberg, Y. T. Grohn, and Y. H. Schukkent. 2001. Cow- and quarter-level risk factors for Streptococcus uberis and Staphylococcus aureus mastitis. J. Dairy Sci. 84:2649-2663.

Zadoks, R. N., H. G. Allore, T. J. Hagenaars, H. W. Barkema, and Y. H. Schukken. 2002. A mathematical model of Staphylococcus aureus control in dairy herds. Epidemiol. Infect. 129:397-416. 